\title{
Iranian Endocrine Society Guidelines for Screening, Diagnosis, and Management of Gestational Diabetes Mellitus
}

\author{
Majid Valizadeh (iD ${ }^{1}$, Farhad Hosseinpanah (iD ${ }^{1,{ }^{*}}$, Fahimeh Ramezani Tehrani ${ }^{2}$, Hengameh Abdi $^{3,{ }^{* *},}$ \\ Ladan Mehran ${ }^{3}$, Farzad Hadaegh ${ }^{4}$, Atieh Amouzegar ${ }^{3}$, Farzaneh Sarvghadi (iD ${ }^{3}$, Fereidoun Azizi ${ }^{3}$ and \\ Iranian Endocrine Society Task Force
}

${ }^{1}$ Obesity Research Center, Research Institute for Endocrine Sciences, Shahid Beheshti University of Medical Sciences, Tehran, Iran

${ }^{2}$ Reproductive Endocrinology Research Center, Research Institute for Endocrine Sciences, Shahid Beheshti University of Medical Sciences, Tehran, Iran

${ }^{3}$ Endocrine Research Center, Research Institute for Endocrine Sciences, Shahid Beheshti University of Medical Sciences, Tehran, Iran

${ }^{4}$ Prevention of Metabolic Disorders Research Center, Research Institute for Endocrine Sciences, Shahid Beheshti University of Medical Sciences, Tehran, Iran

"Corresponding author: Obesity Research Center, Research Institute for Endocrine Sciences, Shahid Beheshti University of Medical Sciences, Tehran, Iran. Email: fhospanah@endocrine.ac.ir

${ }^{* *}$ Corresponding author: Endocrine Research Center, Research Institute for Endocrine Sciences, Shahid Beheshti University of Medical Sciences, Tehran, Iran. Email: abdi@endocrine.ac.ir

Received 2020 August 02; Revised 2020 October 12; Accepted 2020 November 14.

\begin{abstract}
Context: Gestational diabetes mellitus (GDM) is an important endocrine disorder in perinatology, associated with several maternal and neonatal complications. Development of national guidelines can inform clinicians, health policymakers, and researchers about the most recent evidence and practical issues of diagnosis and management of GDM.

Objectives: We aimed to develop clinical practice guidelines for the diagnosis and management of GDM in Iranian pregnant women.

Evidence Acquisition: The Iranian Endocrine Society constituted a task force, consisting of obstetrician-gynecologists, endocrinologists, a clinical nutritionist, a clinical epidemiologist, and a librarian, to review the published literature and propose national guidelines for the diagnosis and management of GDM. The consensus was reached on all recommendations in several group meetings with a majority decision. The evidence and recommendations were graded according to the American College of Physicians' Guideline Grading System.

Results: The proposed guidelines included recommendations for screening, diagnosis, and management of GDM in Iran.

Conclusions: By using an evidence-based approach, these national GDM guidelines can address important clinical issues in the diagnosis and management of Iranian women with GDM.
\end{abstract}

Keywords: Iran, Disease Management, Screening, Guideline, Gestational Diabetes Mellitus (GDM)

\section{Context}

Gestational diabetes mellitus (GDM) is defined as any degree of glucose intolerance, with the onset or first detection during pregnancy (1). Previous studies have reported the association of GDM with the risk of adverse pregnancy outcomes, such as preeclampsia, macrosomia, and shoulder dystocia, which may lead to operative vaginal delivery and birth trauma. Gestational diabetes mellitus is also associated with unfavorable long-term outcomes, such as the development of type 2 diabetes in mothers and obesity, diabetes mellitus (DM), and cardiovascular diseases in offspring $(2,3)$. On the other hand, the early diagnosis and management of GDM can prevent macrosomia, shoulder dystocia, preeclampsia, and hypertensive disorders dur- ing pregnancy (4). Therefore, screening for diagnosis and management of GDM is of paramount importance.

The prevalence of GDM varies greatly from $0.6-3.6 \%$ in North Europe to $6.3 \%$ in Italy due to various diagnostic criteria in different populations (5). Along with an increase in the prevalence of risk factors for diabetes, such as obesity, high maternal age, and family history of DM, GDM has also shown an increasing trend (e.g., 6 - 7\% in the United States and $7.1 \%$ in India $)(2,6)$. According to a recent systematic review, the overall prevalence of GDM, based on the diagnostic criteria of the International Association of Diabetes in Pregnancy Study Group (IADPSG), is $10.6 \%$ versus a pooled overall prevalence of $4.4 \%$, regardless of the type of screening thresholds (7).

Moreover, a systematic review of all studies conducted

Copyright (c) 2020, International Journal of Endocrinology and Metabolism. This is an open-access article distributed under the terms of the Creative Commons Attribution-NonCommercial 4.0 International License (http://creativecommons.org/licenses/by-nc/4.0/) which permits copy and redistribute the material just in noncommercial usages, provided the original work is properly cited. 
up to 2012 in Iran reported the overall prevalence of GDM to be $3.4 \%$ based on old diagnostic criteria, ranging widely from $1.3 \%$ to $18.5 \%$ (8). On the other hand, the increasing prevalence of overweight and obesity in recent years has been associated with the increasing prevalence of GDM, based on the IADPSG criteria, which exceeds all previous records. In this regard, two recent Iranian studies from Isfahan (9) and Tehran (10) reported the higher prevalence of GDM based on the IADPSG criteria (15.6\% and 9.3\%, respectively) than based on the old two-step criteria (7.1\% and $4.2 \%$, respectively). Moreover, two recent meta-analyses, one including nine observational studies and one including four clinical trials, showed adverse pregnancy and prenatal outcomes in GDM patients diagnosed by either method. However, the associations were stronger in the two-step approach than in the one-step approach $(11,12)$.

Considering the mentioned conflicting results, the World Health Organization (WHO) suggested that the final decision about screening, diagnosis, and management of GDM be made for each country, depending on the prevalence rates, risk factors, per capita health expenditure, local obstacles, resources, and priorities of that particular country. To follow this recommendation, Ramezani et al. have conducted a randomized community non-inferiority trial among more than 30,000 pregnant women in five different regions of Iran (13). The participants were randomly assigned to one of the five GDM screening methods (including one-step and two-step methods), based on various cutoff points for fasting plasma glucose (FPG) and abnormal results for GDM diagnosis. The pregnancy outcomes, quality of life, and cost of healthcare are recorded in detail. The results of this study can provide valuable evidence on the diagnosis and management of GDM, as prevention of adverse outcomes of GDM can be cost-effective.

\section{Evidence Acquisition}

The Iranian Endocrine Society constituted a task force, consisting of obstetrician-gynecologists, endocrinologists, a clinical nutritionist, a clinical epidemiologist, and a librarian, to review the published literature and prepare a national guideline for the diagnosis and management of GDM. International and national clinical practice guidelines and consensuses, systematic reviews, and their references were reviewed. Several group meetings were held, and a consensus was reached on all recommendations with a majority decision. To formulate evidence-based recommendations, the Iranian Endocrine Society task force followed the approach recommended by the American College of Physicians' Guideline Grading System (Table 1) (14).

\section{Results}

3.1. Screening and Management of Diabetes Before and During Pregnancy

\subsubsection{Evaluation of Dysglycemia Before Pregnancy}

Question 1: Who should be assessed for dysglycemia among women contemplating pregnancy?

Recommendation 1: Among women who present for preconception counseling, all non-diabetic women with at least one of the known risk factors must be screened for dysglycemia (Strong recommendation, low-quality evidence). Box 1 presents the known risk factors for GDM.

Question 2: How should women at risk for dysglycemia be screened before pregnancy, and what are the diagnostic criteria?

Recommendation 2: The screening tests and diagnostic criteria for women before pregnancy are similar to those for non-pregnant women (Strong recommendation, low-quality evidence). Considering the ease, feasibility, and availability, we suggest the measurement of fasting plasma glucose (FPG). Table 2 summarizes the diagnostic criteria for glucose intolerance before pregnancy.

Question 3: How should women with glucose intolerance be followed up?

Recommendation 3: Women with impaired fasting glucose (IFG) are recommended to adhere to an appropriate diet and moderate-intensity exercise (30 min per day or 150 min per week). In overweight and obese women, the goal of non-pharmacological measures is to achieve at least 7\% weight loss (Strong recommendation, low-quality evidence).

There is no strong evidence that pre-gestational IFG can lead to fetal loss or abnormalities; however, women with IFG should be more careful due to the higher risk of GDM (20). There is also insufficient evidence regarding the effect of preventive metformin therapy on the risk of pregnancy complications or GDM (21).

Recommendation 4: Metformin is not recommended for the prevention of GDM in women with polycystic ovary syndrome (PCOS) and infertility, who become pregnant while taking metformin (Strong recommendation, moderate-quality evidence).

Overall, in women with PCOS and infertility, who become pregnant while taking metformin, there is no strong evidence regarding the preventive effect of metformin on the risk of GDM; however, metformin seems to reduce the risk of fetal loss during the first trimester (22).

\subsubsection{Diagnosis of Diabetes During Pregnancy}

\subsubsection{Diabetes Screening in the First Prenatal Visit}

Question 4: Who should be evaluated for diabetes in the first prenatal visit and what are the recommended 


\begin{tabular}{lcc}
\hline Table 1. The American College of Physicians' Guideline Grading System (14) & & Strength of Recommendation \\
\hline Quality of Evidence & Strong & Benefits Finely Balanced with Risks and Burden \\
\cline { 2 - 3 } & Benefits Clearly Outweigh Risks and Burden OR & Strong \\
\hline High & Strong & Weak \\
\hline Moderate & Weak & Weak \\
\hline
\end{tabular}

\begin{tabular}{|c|}
\hline Risk Factors \\
\hline 1. Previous history of GDM \\
\hline 2. History of diabetes mellitus in first-degree relatives \\
\hline 3. Known glucose intolerance \\
\hline 4. Obesity (BMI $\left.\geq 30 \mathrm{~kg} / \mathrm{m}^{2}\right)$ \\
\hline 5. Low physical activity ${ }^{\mathrm{a}}(18,19)$ \\
\hline 6. History of polycystic ovarian syndrome (PCOS) \\
\hline 7. History of hypertension and/or taking antihypertensive medication \\
\hline 8. Serum TG $>250 \mathrm{mg} / \mathrm{dL}$ and/or $\mathrm{HDL}<35 \mathrm{mg} / \mathrm{dL}$ \\
\hline 9. History of stillbirth ${ }^{\mathrm{b}}$ \\
\hline 10. History of congenital anomalies or macrosomia ${ }^{c}$ in the offspring \\
\hline $\begin{array}{l}\text { Abbreviations: BMI, body mass index; TG, triglycerides; HDL, high-density } \\
\text { lipoprotein. } \\
\text { a Physical activity level is defined as low (MET }<600 \mathrm{~min} / \text { week), moderate (MET } \\
600 \text { - } 1499 \mathrm{~min} / \text { week), and high (MET } \geq 1500 \mathrm{~min} / \text { week), based on the Persian- } \\
\text { translated Modifiable Activity Questionnaire (MAQ). } \\
\text { bStillbirth refers to intrauterine fetal death after } 20 \text { weeks of gestation. } \\
{ }^{\mathrm{c} B i r t h} \text { of an infant } \geq 4000 \mathrm{~g} \text {. }\end{array}$ \\
\hline
\end{tabular}

\begin{tabular}{lccc}
\hline \multicolumn{1}{l}{ Table 2. Diagnostic Criteria for Glucose } & Intolerance Before Pregnancy \\
\hline & Normal & \\
\hline & Prediabetes & Diabetes \\
\hline Fasting plasma glucose $(\mathbf{m g} / \mathbf{d L})$ & $<100$ & $100-125$ & $\geq 126$ \\
$\begin{array}{l}\text { Two-hour plasma glucose } \\
\text { during OGTT (mg/dL) }\end{array}$ & $<140$ & $140-199$ & $\geq 200$ \\
HbA1C (\%) & $<5.7$ & $5.7-6.4$ & $\geq 6.5$ \\
\hline $\begin{array}{l}\text { a Having a random plasma glucose } \geq 200 \mathrm{mg} / \mathrm{dL} \text { with classic symptoms of hy- } \\
\text { perglycemia is also defined as diabetes. }\end{array}$ \\
$\begin{array}{l}\text { b In the absence of overt hyperglycemia, the diagnosis should be based on two } \\
\text { abnormal tests, the same or different tests. }\end{array}$
\end{tabular}

tests?

Recommendation 5: Fasting plasma glucose must be measured (at least eight hours after the last meal) in all women with normal glucose homeostasis in the past year and no history of diabetes, presenting for their first prenatal visit (Strong recommendation, low-quality evidence).

Due to the outbreak of obesity, diabetes has become more prevalent at a young age during fertility years. There- fore, there are concerns about undetected diabetes during pregnancy and its adverse effects on the mother and the fetus. There has been an increasing trend of overweight, obesity, and abdominal obesity in Iran, which are more common among women than men (23-26). Many scientific communities, including the American Diabetes Association, have recommended screening in the first prenatal visits only for women with diabetes risk factors, based on the pre-gestational criteria. The American College of Obstetricians and Gynecologists (ACOG) has also made similar recommendations for diabetes screening in early pregnancy. Generally, the best screening method in early pregnancy has not been defined yet. However, due to the low cost of test and also the increasing prevalence of overweight and obesity in Iran, we recommend FPG measurement in the first prenatal visit.

Question 5: What are the diagnostic criteria for diabetes in early pregnancy and how are the results interpreted?

Recommendation 6: In the first prenatal visit, pregnant women with FPG $\geq 126 \mathrm{mg} / \mathrm{dL}$ in at least two separate sample tests (without delay) are diagnosed with overt diabetes, and no further screening tests with glucose load are needed (Strong recommendation, high-quality evidence).

Recommendation 7: Women with random plasma glucose levels above $200 \mathrm{mg} / \mathrm{dL}$ in the presence of classic symptoms of diabetes are diagnosed with overt diabetes (Strong recommendation, high-quality evidence).

Recommendation 8: In the first prenatal visit, GDM is diagnosed by an FPG level of $100-125 \mathrm{mg} / \mathrm{dL}$, even in one single measurement (Strong recommendation, lowquality evidence).

Recommendation 9: Women with negative screening in early pregnancy, i.e., $\mathrm{FPG}<100 \mathrm{mg} / \mathrm{dL}$, are recommended to be screened at $24-28$ weeks of gestation (see below) (Strong recommendation, high-quality evidence).

Table 3 shows the diagnostic criteria for glucose intolerance based on FPG levels in the first prenatal visit.

Question 6: Which treatment is used for GDM in early pregnancy?

Recommendation 10: It is recommended for preg- 
Table 3. Diagnostic Criteria for Glucose Intolerance Based on Fasting Plasma Glucose Levels $(\mathrm{mg} / \mathrm{dL})$ in the First Prenatal Visit

\begin{tabular}{lc}
\hline Fasting Plasma Glucose Levels $(\mathbf{m g} / \mathbf{d L})$ & Glucose Intolerance \\
\hline$<\mathbf{1 0 0}$ & Normal \\
$\mathbf{1 0 0 - 1 2 5}$ & Gestational diabetes \\
$\geq \mathbf{1 2 6}^{\text {a }}$ & Overt or pre-gestational diabetes \\
\hline
\end{tabular}

${ }^{\text {a }}$ Should be confirmed with another separate sample test.

nant women with GDM diagnosed in early pregnancy to adhere to an appropriate diet, physical activity, and insulin therapy if needed (Weak recommendation, low-quality evidence).

Although there is no strong evidence regarding the effect of GDM treatment in early pregnancy, appropriate diet, increased physical activity, self-monitoring of blood glucose (SMBG), and drug therapy (if needed) are recommended for women diagnosed with GDM in early pregnancy.

Question 7: Is hemoglobin A1c (HbA1c) measurement used for the diagnosis of GDM in early pregnancy?

Recommendation 11: At present, the measurement of HbA1c is not recommended for the diagnosis of GDM in Iran (Strong recommendation, low-quality evidence).

Question 8: Are oral anti-diabetic agents recommended for glycemic control in women with GDM diagnosed in early pregnancy?

Recommendation 12: Prescription of oral antidiabetic agents is not recommended during the first trimester of pregnancy (Strong recommendation, lowquality evidence).

Question 9: What are the glycemic goals in the management of GDM diagnosed in early pregnancy?

Recommendation 13: The treatment goals during the first trimester of pregnancy are not different from those of other trimesters and include FPG $<95 \mathrm{mg} / \mathrm{dL}$, one-hour postprandial glucose $(\mathrm{PPG})<140 \mathrm{mg} / \mathrm{dL}$, and two-hour PPG $<120 \mathrm{mg} / \mathrm{dL}$ (Weak recommendation, low-quality evidence).

These treatment goals are based on the suggested values for the second half of pregnancy because there is no conclusive evidence regarding the plasma glucose level during the first half of pregnancy.

Figure 1 depicts the screening and management of glucose tolerance status in the first prenatal visit.

\subsubsection{Screening Diabetes in Pregnant Women with Negative First Screening for GDM}

Question 10: Who should be screened for GDM at 24 28 weeks of gestation?

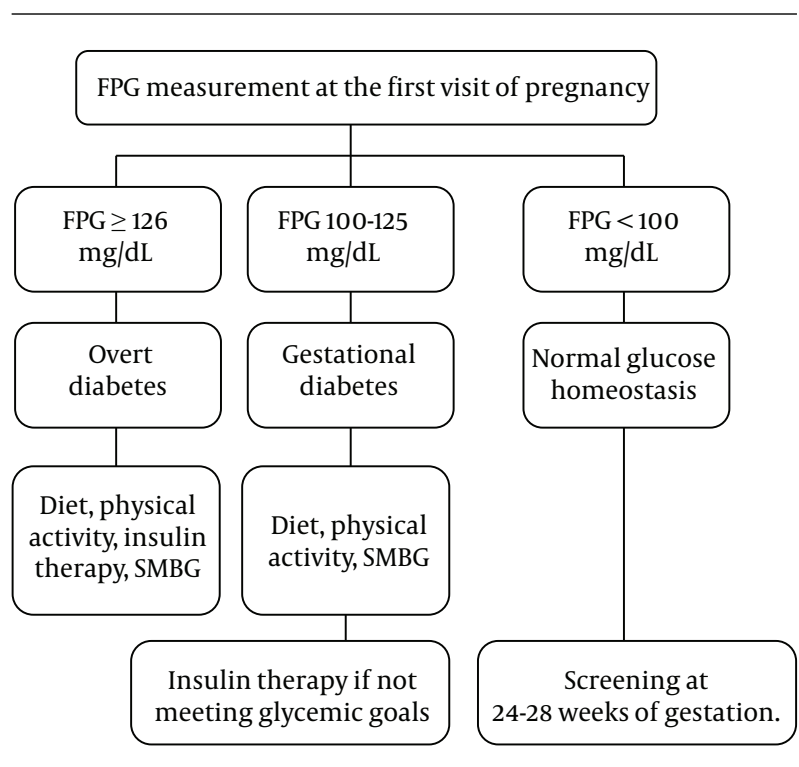

Figure 1. Algorithm for the screening of diabetes at the first visit of pregnancy. $\mathrm{Ab}$ breviations: FPG, fasting plasma glucose; SMBG, self-monitoring of blood glucose.

Recommendation 14: All pregnant women with negative screening results $(\mathrm{FPG}<100 \mathrm{mg} / \mathrm{dL}$ ) in earlier evaluations should be screened for GDM at $24-28$ weeks of gestation (Strong recommendation, moderate-quality evidence).

Question 11: What are the tests used for screening of GDM at 24 - 28 weeks of gestation?

Recommendation 15: For GDM screening at 24 - 28 weeks of gestation, a two-step glucose tolerance test (GTT) is recommended (Weak recommendation, low-quality evidence).

There is no consensus regarding the best screening method for GDM due to the lack of outcome-based surveys comparing different methods. Overall, the proposed methods may vary in different populations. The two-step approach, using $50 \mathrm{~g}$ of glucose in the first step, is the most common screening approach in many countries.

Various recommendations and guidelines have been proposed by international scientific communities for the detection of GDM (6). However, there have been major controversies over the diagnosis of GDM, using one-step or two-step GTT, based on different glucose thresholds because of inconclusive evidence about these methods for the detection of GDM in pregnant women.

Question 12: What thresholds are considered positive in the $50 \mathrm{~g}$ Glucose Challenge Test (GCT)?

Recommendation 16: In GCT with $50 \mathrm{~g}$ oral glucose, a plasma glucose level of $\leq 140 \mathrm{mg} / \mathrm{dL}$ is considered to be normal (Strong recommendation, moderate-quality evidence). 
Recommendation 17: Gestational diabetes mellitus is diagnosed if one-hour plasma glucose exceeds $200 \mathrm{mg} / \mathrm{dL}$ in $50 \mathrm{~g}$ GCT (Strong recommendation, moderate-quality evidence).

Different thresholds of 130, 135, and $140 \mathrm{mg} / \mathrm{dL}$ have been recommended for GCT, with lower thresholds leading to a higher false-positive rate. Accordingly, ACOG has recommended using higher thresholds (27). Table 4 summarizes the recommended diagnostic criteria of GCT by the task force.

\begin{tabular}{lc}
\hline $\begin{array}{l}\text { Table 4. Diagnostic Criteria of Glucose Challenge Test (GCT) for Pregnant Women } \\
\text { without a History of Diabetes at } 24-28 \text { Weeks of Gestation }\end{array}$ \\
$\begin{array}{lc}\text { One-Hour Plasma Glucose in GCT with } \mathbf{5 0} \text { g Oral } \\
\text { Glucose Solution }(\mathbf{m g} / \mathbf{d L})\end{array}$ & Glucose Intolerance \\
\hline$<\mathbf{1 4 0}$ & Normal \\
$\geq \mathbf{2 0 0}$ & Gestational diabetes \\
$\mathbf{1 4 0}-\mathbf{1 9 9}$ & OGTT $^{\text {a }}$ \\
\hline
\end{tabular}

${ }^{\mathrm{a}}$ 100-g oral glucose tolerance test (Table 5).

Question 13: How should pregnant women with positive test results in the first step be evaluated?

Recommendation 18: Patients with one-hour plasma glucose levels of $140-199 \mathrm{mg} / \mathrm{dL}$ in GCT are recommended to undergo $100 \mathrm{~g}$ oral glucose tolerance test(OGTT) after at least eight hours of fasting to measure the plasma glucose levels at one, two, and three hours after receiving glucose (Strong recommendation, low-quality evidence).

Question 14: What are the criteria for GDM diagnosis using $100 \mathrm{~g}$ OGTT?

Recommendation 19: Gestational diabetes mellitus is diagnosed if plasma glucose levels meet or exceed the cutoff points in at least two OGTT samples, I.e., FPG $\geq$ $95 \mathrm{mg} / \mathrm{dL}$, one-hour PG $\geq 180 \mathrm{mg} / \mathrm{dL}$, two-hour PG $\geq 155$ $\mathrm{mg} / \mathrm{dL}$, and three-hour $\mathrm{PG} \geq 140 \mathrm{mg} / \mathrm{dL}$.

A recent systematic review and meta-analysis of 26 studies reported a higher rate of adverse pregnancy outcomes in women with one abnormal result of $100 \mathrm{~g}$ OGTT than in those with normal results in all four samples (28); accordingly, the last ACOG practice bulletin noted that we may diagnose GDM based on one elevated result in $100 \mathrm{~g}$ OGTT (29).

Recommendation 20: One-step GTT with $75 \mathrm{~g}$ oral glucose after overnight fasting, with plasma glucose measurements during fasting and one and two hours post-loading, is unhindered.

Question 15: What are the criteria for GDM diagnosis with $75 \mathrm{~g}$ oral glucose?

Recommendation 21: In one-step GTT with $75 \mathrm{~g}$ glucose, FPG $\geq 92 \mathrm{mg} / \mathrm{dL}$, one-hour PG $\geq 180 \mathrm{mg} / \mathrm{dL}$, and twohour PG $\geq 153 \mathrm{mg} / \mathrm{dL}$ are considered abnormal, and GDM is diagnosed even if one criterion is met. Table 5 presents the diagnostic criteria of GDM using two-step and one-step approaches.

Figure 2 demonstrates the two-step approach for GDM screening at 24 - 28 weeks of gestation.

Recommendation 22: Following the diagnosis of GDM, based on any of the abovementioned guidelines, repeating GTT is not necessary (Strong recommendation, low-quality evidence).

Recommendation 23: If a prenatal complication suggestive of GDM (e.g., macrosomia, polyhydramnios, and fetal waist circumference $\geq$ 90th percentile) occurs, GTT should be repeated even for women with normal previous evaluations (Strong recommendation, low-quality evidence).

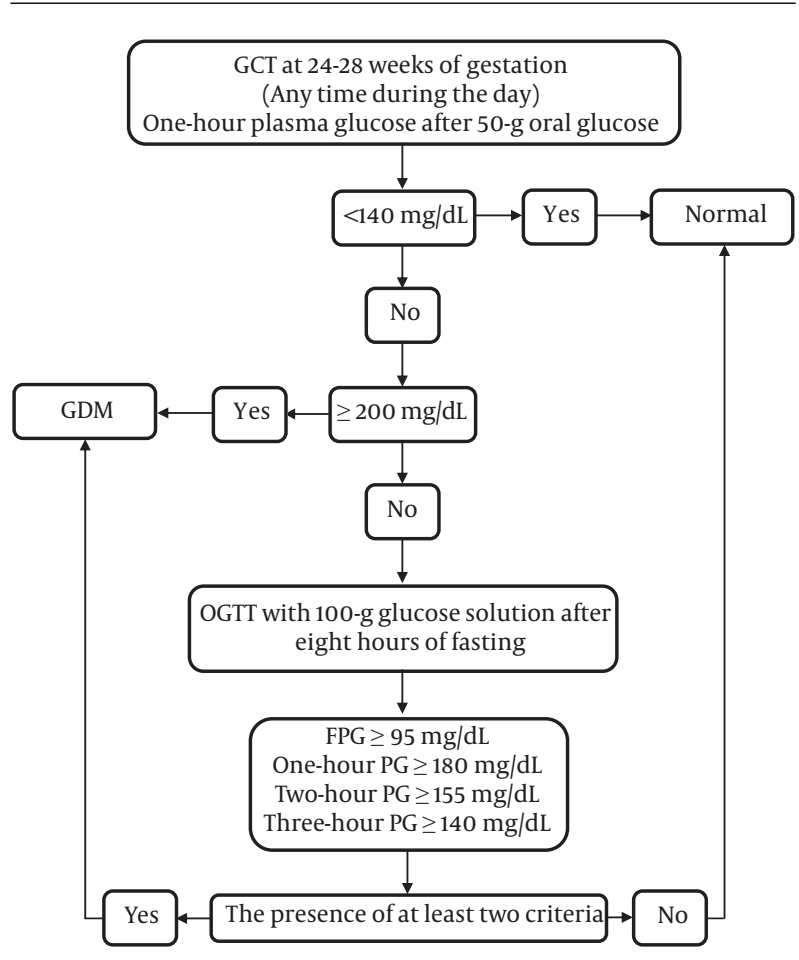

Figure 2. The two-step approach for GDM screening at 24 - 28 weeks of gestation. Abbreviations: GCT, Glucose Challenge Test; OGTT, Oral Glucose Tolerance Test; FPG, Fasting Plasma Glucose; GDM, Gestational Diabetes Mellitus.

This recommendation is based on the findings of studies that showed that repeated screening can detect additional cases of GDM, especially in high-risk women $(31,32)$. In such cases, the use of the one-step approach with $75 \mathrm{~g}$ oral glucose or a two-step approach (considered positive with only one abnormal glucose result) is less risky.

\subsubsection{Management of GDM}

Question 16: How GDM should be managed? 


\begin{tabular}{|c|c|c|}
\hline Measurement Time & $100 \mathrm{~g}$ OGTT in Two-Step Approach with Carpenter and Coustan Criteria (30) ${ }^{a}$ & One-Step Approach with $75 \mathrm{~g}_{\text {OGTT }}{ }^{\mathrm{b}}$ \\
\hline Fasting plasma glucose & $95 \mathrm{mg} / \mathrm{dL}$ & $92 \mathrm{mg} / \mathrm{dL}$ \\
\hline One-hour plasma glucose & $180 \mathrm{mg} / \mathrm{dL}$ & $180 \mathrm{mg} / \mathrm{dL}$ \\
\hline Two-hour plasma glucose & $155 \mathrm{mg} / \mathrm{dL}$ & $153 \mathrm{mg} / \mathrm{dL}$ \\
\hline Three-hour plasma glucose & $140 \mathrm{mg} / \mathrm{dL}$ & \\
\hline
\end{tabular}

Recommendation 24: The management of GDM at 24 - 28 weeks of gestation includes appropriate diet, increasing physical activity (at least $150 \mathrm{~min} /$ week), and drug therapy, if needed (Strong recommendation, high-quality evidence).

Since interventions reducing the serum glucose level improve the outcomes of GDM, especially shoulder dystocia and delivery of a large-for-gestational-age (LGA) infant, the treatment of pregnant women with GDM is effective (33).

\section{General Considerations for Diet Therapy:}

Recommendation 25: The goals of therapy may be achieved by controlling calorie intake, tailored to maternal and neonatal needs so that the mother can gain proper weight during pregnancy by dividing her meal intake and avoiding long fasting (Strong recommendation, highquality evidence).

Question 17: Which diet is appropriate for GDM patients?

Recommendation 26: It is recommended to receive $20 \%$ of calorie intake from proteins, $50 \%$ from carbohydrates, and 30\% from fat with a proper distribution(Strong recommendation, low-quality evidence).

- In GDM patients, calorie intake should consist of 50\% carbohydrate, $30 \%$ fat, and $20 \%$ protein. The diet should include at least three units of low-fat dairy; the use of more units depends on the energy requirements of the individual.

- Total carbohydrate intake should be divided into three main courses and three snacks. Individuals under insulin therapy should receive $15 \%$ carbohydrate $(\mathrm{CHO})$ in the morning, $10-15 \%$ CHO in the first snack, 20 - 25\% CHO in the lunch meal, 10 - 15\% CHO in the second snack, 20 - 25\% CHO in the dinner meal, and $15 \% \mathrm{CHO}$ in the dinner snack ( $\mathrm{CHO}$ should be increased for the dinner snack). Individuals who are managed without insulin therapy should receive $15 \%$ CHO in the morning, $10-15 \%$ CHO in the first snack, 20-25\% $\mathrm{CHO}$ in the lunch meal, 10-15\% CHO in the second snack, 20 - 25\% CHO in the dinner meal, and 10\% CHO in the dinner snack.
- For each 1000 calorie intake, $14 \mathrm{~g}$ of fiber should be received, including five units from vegetables, four units from fruits, and one unit from cereals (whole grains mostly).

- Simple sugars can account for up to $10 \%$ of calorie intake; however, it is more favorable to limit the intake of simple sugars to $5 \%$ of calorie intake.

Question 18: Is exercise recommended for women with GDM?

Recommendation 27: Moderate physical activity is recommended for all pregnant women with GDM, and there are no exercise restrictions for controlling blood glucose (Strong recommendation, low-quality evidence).

Exercise, if not prohibited during pregnancy, may postpone or resolve the need for pharmacological therapy. Although aerobic training is more favorable, endurance training may be also helpful. Moderate-intensity training is recommended for at least $\mathbf{3 0}$ minutes daily, four to five days a week. Women without physical fitness should start physical activity at low intensity (15 minutes daily) and gradually increase the duration of training.

Question 19: What are the goals of therapy to control blood glucose in GDM?

Recommendation 28: The goal of therapy after 24 weeks of gestation is to reach FPG $<95 \mathrm{mg} / \mathrm{dL}$, one-hour PPG $\leq 140 \mathrm{mg} / \mathrm{dL}$, and two-hour PPG $\leq 120 \mathrm{mg} / \mathrm{dL}$ (Strong recommendation, low-quality evidence).

The goals of therapy for GDM women at this stage are not different from those of pregnant women who are diagnosed earlier. It is strongly recommended to reduce the FPG level to $<95 \mathrm{mg} / \mathrm{dL}$. According to some low-quality evidence, one-hour plasma glucose $\leq 140 \mathrm{mg} / \mathrm{dL}$ and twohour plasma glucose $\leq 120 \mathrm{mg} / \mathrm{dL}$ are recommended. If recurrent hypoglycemia occurs, higher cutoff points by $5-10$ mg can be considered for therapeutic goals.

Question 20: How is blood glucose monitored in women with GDM?

Recommendation 29: It is recommended to measure fasting glucose and two-hour PPG levels using a glucometer four times a day, and if not possible, at least 4 - 8 times a week, after achieving the goals of therapy (Strong recom- 
mendation, low-quality evidence).

Question 21: What is the role of HbA1c measurement in the management of GDM?

Recommendation 30: HbAlc may be helpful for glucose monitoring in pregnancy as the second measure after SMBG (Weak recommendation, low-quality evidence).

In a normal pregnancy, the HbAic level is lower because of increased red blood cell turnover (34). It is suggested to maintain HbA1c in pregnancy $<6 \%$ if it can be achieved without significant hypoglycemia. It should be noted that most data on this subject are related to pregnant women with pregestational diabetes (35).

Question 22: What is the preferred pharmacologic intervention in GDM?

Recommendation 31: Insulin is the drug of choice for women with GDM who cannot meet the therapeutic goals, despite non-pharmacological interventions.

Question 23: What are the indications for oral antidiabetic agents in GDM?

Recommendation 32: Oral anti-diabetic agents, especially metformin, can be used after 24 weeks of gestation in women with FPG $\leq 110 \mathrm{mg} / \mathrm{dL}$ (Weak recommendation, moderate-quality evidence).

Metformin is suggested for women with mild GDM (FPG $\leq 110 \mathrm{mg} / \mathrm{dL}$ ), unwilling to use insulin (36). However, $30 \%$ of these women need to shift to insulin in the next weeks of gestation. Glibenclamide (glyburide) should be considered as the last option due to the possible increase in neonatal hypoglycemia, overweight, and macrosomia (37). As mentioned earlier, therapy with oral antidiabetic drugs is not recommended during early pregnancy. Nevertheless, if a pregnant woman is treated with metformin due to other reasons before pregnancy, therapy with metformin can be continued (38).

\subsection{Postpartum Recommendations}

Question 24: How is a postpartum follow-up in women with GDM?

Recommendation 33: All women with GDM should be evaluated using standard 2-hour $75 \mathrm{~g}$ OGTT at 4 - 12 weeks after delivery. The interpretation of the results is similar to non-pregnant cases (Strong recommendation, low-quality evidence).

Recommendation 34: In women with normal OGTT after delivery, the annual measurement of FPG is recommended (Strong recommendation, low-quality evidence).

Recommendation 35: For all prediabetic women diagnosed after delivery, lifestyle modifications (exercise and diet), with or without metformin therapy, are recommended (Strong recommendation, high-quality evidence).

Gestational diabetes mellitus usually resolves after delivery, as hormones secreted from the placenta, as the main source of insulin resistance, are removed from the body (39). Therefore, the need for drug therapy mostly resolves after delivery although these patients are at risk of type 2 diabetes, which may occur in $50 \%$ of women in the next 20 years $(40,41)$. Women who develop GDM at younger gestational ages or those who require a higher insulin dosage are at a higher risk of type 2 diabetes. Therefore, pregnant women with GDM should be followed up after delivery (42).

\subsection{Technical Remarks Related to OGTT}

- There is no need for fasting in $50 \mathrm{~g}$ OGTT, while other tests require at least eight hours of fasting.

- Diet for three days before OGTT should not be constrained (at least $150 \mathrm{~g}$ of carbohydrate daily), and physical activity should be done routinely.

- Glucose anhydrous (75 g), diluted in water (300 mL), should be used within five minutes; a cool solution is better tolerated.

- Individuals should avoid smoking, physical activity, and intake of food, tea, or coffee during OGTT.

- Only outpatient tests should be performed. The likelihood of false-positive results may increase in inpatients or immobile individuals.

\subsection{Obstetric care for GDM}

Question 25: Which special obstetric care should be considered for women with GDM?

Recommendation 36: The fetal viability and gestational age should be confirmed at 7-9 weeks of gestation (Strong recommendation, high-quality evidence).

Recommendation 37: If GDM is diagnosed before 14 weeks of gestation, and there are additional risk factors (e.g., history of cardiac malformation in first-degree relatives of the fetus, obesity, or a history of GDM), an early detailed anatomy ultrasound is recommended at 11-14 weeks of gestation to exclude severe fetal malformations (Strong recommendation, low-quality evidence).

Recommendation 38: Similar to pregnant women without GDM, the first-trimester screening for chromosomal abnormalities, especially Down syndrome (trisomy 21) and trisomy 18, is recommended between weeks 11 and 14 of gestation. This type of screening includes nuchal translucency (NT) ultrasound, as well as the measurement of pregnancy-associated plasma protein-A (PAPP-A) and human chorionic gonadotropin (HCG) in the mother's blood (Strong recommendation, low-quality evidence).

Gestational diabetes mellitus is associated with an increased risk of maternal and fetal complications both during pregnancy and in the postpartum period. Screening and identification of these high-risk women are important 
for improving short- and long-term maternal and fetal outcomes (43-45).

Question 26: Which fetal health and growth assessments should be performed in women with GDM?

Recommendation 39: An ultrasound monitoring of fetal growth and amniotic fluid volume is recommended for all women with GDM at 28 to 36 weeks of gestation (weak recommendation, low-quality evidence).

Recommendation 40: Periodic clinical assessments and sonographic growth analysis, if needed, are recommended from the time of diagnosis until term delivery (Strong recommendation, low-quality evidence).

Recommendation 41: Antenatal fetal testing is usually initiated at 32 weeks of gestation for women with poorly controlled or medication-requiring GDM, without other comorbidities (Strong recommendation, lowquality evidence).

Recommendation 42: Fetal health tests are recommended at 38 and 39 weeks of gestation (Strong recommendation, low-quality evidence).

Recommendation 43: Routine monitoring of fetal health using methods, such as umbilical arterial Doppler assessment, fetal heart rate monitoring, and biophysical profile test, before 38 weeks of gestation is not recommended for pregnant women with GDM unless there is a risk of fetal growth restriction (Strong recommendation, low-quality evidence).

The risk of fetal demise is increased in patients with suboptimal glycemic control. Hence, fetal surveillance may be valuable in women with poorly controlled GDM. Since macrosomia and shoulder dystocia are more common in women with GDM, the assessment of fetal growth via ultrasonography or clinical examination in the third trimester is reasonable to detect macrosomia. There is no consensus regarding antepartum fetal testing in women with well-controlled GDM, who are not medically treated. If the clinician decides to perform antepartum testing for these patients, it usually begins later than in women with medically treated GDM $(16,44,46-49)$.

Question 27: What are delivery considerations (timing and mode of delivery) for pregnancies complicated by GDM?

Recommendation 44: In women with GDM, controlled with diet and exercise, delivery should not be planned before 39 weeks of gestation, unless otherwise indicated. In this setting, expectant management up to 41 weeks of gestation, as indicated by antepartum testing, is generally appropriate (Strong recommendation, highquality evidence).

Recommendation 45: In women with wellcontrolled, medically treated GDM, delivery is recommended at 39 to 40 weeks of gestation (Strong recommen- dation, low-quality evidence).

Recommendation 46: Delivery between 37 and 39 weeks of gestation may be justified only after incorporating tradeoffs between the risk of prematurity and stillbirth (Weak recommendation, low-quality evidence).

Recommendation 47: Late preterm delivery from 34 to 37 weeks of gestation should be performed for women who fail to reach glycemic control even following a hospital admission or those with abnormal antepartum fetal testing results (Strong recommendation, low-quality evidence).

Recommendation 48: The estimated fetal weight $<$ $3800 \mathrm{~g}$ at 38 - 39 weeks of gestation, poor glycemic control, poor compliance with treatment, history of stillbirth, and cardiovascular diseases should be considered as indications for labor induction (Strong recommendation, lowquality evidence).

Commonly, women with good glycemic control on treatment do not require delivery before 39 weeks of gestation. However, the degree of glycemic control requiring earlier delivery and the timing of delivery is not established. Previous studies suggested the lower incidence of LGA, shoulder dystocia, and cesarean section delivery, besides a higher rate of hyperbilirubinemia, in the group of labor induction at 38 weeks of gestation than in the expectant management group. Delivery of women with GDM at 38 or 39 weeks of gestation reduces the overall perinatal mortality, without increasing the rate of cesarean section. However, there is not enough evidence regarding the necessity of cesarean section to reduce the risk of trauma in the setting of suspected macrosomia $(16,44,46,50)$.

Question 28: When is cesarean delivery recommended in GDM?

Recommendation 49: In pregnancies with an estimated fetal weight $>4000 \mathrm{~g}$ at 38 - 39 weeks of gestation, elective cesarean section is suggested (Weak recommendation, low-quality evidence).

Question 29: Can glucocorticoids be prescribed to improve fetal lung maturation in GDM women?

Recommendation 50: Glucocorticoids can be used for GDM women to improve lung maturation if premature delivery is suspected or definitely determined (Weak recommendation, low-quality evidence).

Question 30: What are the considerations for the use of glucocorticoids?

Recommendation 51: In pregnant women under insulin therapy, who require glucocorticoids for fetal lung maturation, the insulin dose should be increased accordingly. In these cases, hospitalization and blood glucose monitoring are highly recommended (Strong recommendation, low-quality evidence).

In women with GDM and acceptable glycemic control 
without insulin therapy, warning about the risk of hyperglycemia and closer monitoring of blood glucose is advisable if glucocorticoid would be prescribed.

\section{Conclusions}

The current national GDM guideline was developed to address important clinical issues in the diagnosis and management of Iranian women with GDM. However, there are still many knowledge gaps in the diagnosis and management of GDM, and there is inadequate information about the short-and long-term maternal and neonatal outcomes related to current practices. The most important areas of uncertainty include GDM diagnostic criteria, especially in the first half of pregnancy, the effects of different interventions for dysglycemia on maternal, perinatal, and neonatal outcomes, optimal blood sugar thresholds based on the goals of therapy, and safety and efficacy of oral hypoglycemic medications, especially long-term outcomes. We believe that the ongoing study by Ramezani et al. may provide suitable answers to most of these uncertainties. This guideline will be hopefully updated after publishing the results of this national study.

\section{Contributor Information}

\section{Iranian Endocrine Society Task Force:}

Sedigheh Hantoushzadeh, Azamsadat Mousavi, Fatemeh Esfahanian (D), Manouchehr Nakhjavani, Nooshin Shirzad (D), Mojtaba Malek, Mohsen Khoshniat Nikoo, Ashraf Jamal, Mamak Shariat, Solmaz Piri, Sara Kazempour Ardebili and Hossein Delshad

\section{Footnotes}

Authors' Contribution: Study concept and design: M.V., F.H., and F.A.; Acquisition and interpretation of data: M.V., F.H., F. RT., H.A.; Drafting of the manuscript: M.V., F.H., F.RT., H.A., and L.M.; Critical revision of the manuscript for important intellectual content and approval of the final manuscript: F.H., A.A., F.S., and F.A and other members of Iranian Endocrine Society Task Force: Sedigheh Hantoushzadeh (Maternal, Fetal and Neonatal Research Center, Tehran University of Medical Sciences, Tehran, Iran), Azamsadat Mousavi (Imam Khomeini Hospital, Tehran University of Medical Sciences, Tehran, Iran), Fatemeh Esfahanian (Department of Endocrinology, Imam Khomeini Hospital, School of Medicine, Tehran University of Medical Sciences, Tehran, Iran), Manouchehr Nakhjavani(Endocrinology and Metabolic Research Center, Vali-Asr Hospital, Tehran University of Medical Sciences, Tehran, Iran), Nooshin Shirzad (Department of Endocrinology, Vali-Asr Hospital, Endocrinology and Metabolism Research Center, Imam Khomeini Complex Hospital, Tehran University of Medical Sciences, Tehran, Iran), Mojtaba Malek (Research Center for
Prevention of cardiovascular Disease, Institute of Endocrinology and Metabolism, Iran University of Medical Sciences, Tehran, Iran), Mohsen Khoshniat Nikoo (Endocrine and Metabolism Research Center, Tehran University of Medical Sciences, Tehran, Iran), Ashraf Jamal (Shariati Hospital, Tehran University of Medical Sciences, Tehran, Iran), Mamak Shariat (Maternal, Fetal and Neonatal Research Center, Tehran University of Medical Sciences, Tehran, Iran), Solmaz Piri (Director of International Affairs of National Association of Iranian Gynecologists and Obstetricians, Tehran, Iran), Sara Kazempour-Ardebili (Consultant Diabetologist, Tehran, Iran), Hossein Delshad (Endocrine Research Center, Research Institute for Endocrine Sciences, Shahid Beheshti University of Medical Sciences, Tehran, Iran).

Conflict of Interests: The authors declare no conflicts of interest.

Funding/Support: There is no funding.

\section{References}

1. Metzger BE, Coustan DR. Summary and recommendations of the Fourth International Workshop-Conference on Gestational Diabetes Mellitus. The Organizing Committee. Diabetes Care. 1998;21 Suppl 2:B161-7. [PubMed: 9704245].

2. Mission JF, Ohno MS, Cheng YW, Caughey AB. Gestational diabetes screening with the new IADPSG guidelines: a costeffectiveness analysis. Am J Obstet Gynecol. 2012;207(4):326 e1-9. doi: 10.1016/j.ajog.2012.06.048. [PubMed: 22840972]. [PubMed Central: PMC4621259].

3. Reece EA. The fetal and maternal consequences of gestational diabetes mellitus. J Matern Fetal Neonatal Med. 2010;23(3):199-203. doi: 10.3109/14767050903550659. [PubMed: 20121460].

4. WHO Guidelines Approved by the Guidelines Review Committee. Diagnostic criteria and classification of hyperglycaemia first detected in pregnancy. Geneva: World Health Organization; 2013. Available from: https://www.who.int/diabetes/publications/Hyperglycaemia_In_ Pregnancy/en/.

5. Baz B, Riveline JP, Gautier JF. Endocrinology of pregnancy: Gestational diabetes mellitus: Definition, aetiological and clinical aspects. Eur J Endocrinol. 2016;174(2):R43-51. doi: 10.1530/EJE-15-0378. [PubMed: 26431552].

6. Rajput R, Yadav Y, Nanda S, Rajput M. Prevalence of gestational diabetes mellitus \& associated risk factors at a tertiary care hospital in Haryana. Indian J Med Res. 2013;137(4):728-33. [PubMed: 23703340]. [PubMed Central: PMC3724253].

7. Behboudi-Gandevani S, Amiri M, Bidhendi Yarandi R, Ramezani Tehrani F. The impact of diagnostic criteria for gestational diabetes on its prevalence: a systematic review and meta-analysis. Diabetol Metab Syndr. 2019;11:11. doi: 10.1186/s13098-019-0406-1. [PubMed: 30733833]. [PubMed Central: PMC6359830].

8. Jafari-Shobeiri M, Ghojazadeh M, Azami-Aghdash S, Naghavi-Behzad M, Piri R, Pourali-Akbar Y, et al. Prevalence and risk factors of gestational diabetes in Iran: A systematic review and meta-analysis. Iran J Public Health. 2015;44(8):1036-44. [PubMed: 26587467]. [PubMed Central: PMC4645723].

9. Hosseini E, Janghorbani M, Aminorroaya A. Incidence, risk factors, and pregnancy outcomes of gestational diabetes mellitus using onestep versus two-step diagnostic approaches: A population-based cohort study in Isfahan, Iran. Diabetes Res Clin Pract. 2018;140:288-94. doi: 10.1016/j.diabres.2018.04.014. [PubMed: 29649540].

10. Niroomand M, Afsar J, Hosseinpanah F, Afrakhteh M, Farzaneh F, Serahati S. Comparison of the international association of diabetes in 
pregnancy study group criteria with the old American diabetes association criteria for diagnosis of gestational diabetes mellitus. Int J Endocrinol Metab. 2019;17(4). e88343. doi: 10.5812/ijem.88343. [PubMed: 31903093]. [PubMed Central: PMC6935709].

11. Saccone G, Khalifeh A, Al-Kouatly HB, Sendek K, Berghella V. Screening for gestational diabetes mellitus: one step versus two step approach. A meta-analysis of randomized trials. J Matern Fetal Neonatal Med. 2020;33(9):1616-24. doi: 10.1080/14767058.2018.1519543. [PubMed: 30173594].

12. Hosseini E, Janghorbani M. Systematic review and meta-analysis of diagnosing gestational diabetes mellitus with one-step or two-step approaches and associations with adverse pregnancy outcomes. Int J Gynaecol Obstet. 2018;143(2):137-44. doi: 10.1002/ijgo.12644. [PubMed: 30101526].

13. Ramezani Tehrani F, Gulf Study Cooperative Research G. Cost effectiveness of different screening strategies for gestational diabetes mellitus screening: study protocol of a randomized community noninferiority trial. Diabetol Metab Syndr. 2019;11:106. doi: 10.1186/s13098019-0493-z. [PubMed: 31890040]. [PubMed Central: PMC6921504].

14. Qaseem A, Snow V, Owens DK, Shekelle P, Clinical Guidelines Committee of the American College of P. The development of clinical practice guidelines and guidance statements of the American College of Physicians: summary of methods. Ann Intern Med. 2010;153(3):194-9. doi: 10.7326/0003-4819-153-3-201008030-00010. [PubMed: 20679562].

15. Moyer VA, U. S. Preventive Services Task Force. Screening for gestational diabetes mellitus: U.S. Preventive Services Task Force recommendation statement. Ann Intern Med. 2014;160(6):414-20. doi: 10.7326/M13-2905. [PubMed: 24424622].

16. American College of O, Gynecologists' Committee on Practice B.ACOG practice bulletin no. 201: Pregestational diabetes mellitus. Obstet Gynecol. 2018;132(6):e228-48. doi: 10.1097|AOG.0000000000002960. [PubMed: 30461693].

17. Kiani F, Saei Ghare Naz M, Sayehmiri F, Sayehmiri K, Zali H. The risk factors of gestational diabetes mellitus: A systematic review and metaanalysis study. Int J Women's Health Reprod Sci. 2017;5(4):253-63. doi: 10.15296/ijwhr.2017.44.

18. Kriska AM, Knowler WC, LaPorte RE, Drash AL, Wing RR, Blair SN, et al. Development of questionnaire to examine relationship of physical activity and diabetes in Pima Indians. Diabetes Care.1990;13(4):401-11. doi: 10.2337/diacare.13.4.401. [PubMed: 2318100].

19. Pereira MA, FitzerGerald SJ, Gregg EW, Joswiak ML, Ryan WJ, Suminski RR, et al. A collection of physical activity questionnaires for health-related research. Med Sci Sports Exerc. 1997;29(6 Suppl):S1-205. [PubMed: 9243481].

20. Buse JB, Wexler DJ, Tsapas A, Rossing P, Mingrone G, Mathieu C, et al. 2019 update to: Management of hyperglycemia in type 2 diabetes, 2018. A consensus report by the American diabetes association (ADA) and the European association for the study of diabetes (EASD). Diabetes Care. 2020;43(2):487-93. doi: 10.2337/dci19-0066. [PubMed: 31857443]. [PubMed Central: PMC6971782].

21. McIntyre HD, Sacks DA, Barbour LA, Feig DS, Catalano PM, Damm P, et al. Issues with the diagnosis and classification of hyperglycemia in early pregnancy. Diabetes Care. 2016;39(1):53-4. doi: 10.2337/dc15-1887. [PubMed: 26519336].

22. Bidhendi Yarandi R, Behboudi-Gandevani S, Amiri M, Ramezani Tehrani F. Metformin therapy before conception versus throughout the pregnancy and risk of gestational diabetes mellitus in women with polycystic ovary syndrome: a systemic review, meta-analysis and meta-regression. Diabetol Metab Syndr. 2019;11:58. doi: 10.1186/s13098019-0453-7. [PubMed: 31367235]. [PubMed Central: PMC6651943].

23. Mirzazadeh A, Salimzadeh H, Arabi M, Navadeh S, Hajarizadeh B, Haghdoost AA. Trends of obesity in Iranian adults from 1990s to late 2000s; a systematic review and meta-analysis. Middle East J Dig Dis. 2013;5(3):151-7. [PubMed: 24829686]. [PubMed Central: PMC3990178].

24. Noshad S, Abbasi M, Etemad K, Meysamie A, Afarideh M, Khajeh E, et al. Prevalence of metabolic syndrome in Iran: A 2011 update. JDiabetes.
2017;9(5):518-25. doi: 10.1111/1753-0407.12438. [PubMed: 27262869].

25. Barzin M, Valizadeh M, Serahati S, Mahdavi M, Azizi F, Hosseinpanah F. Overweight and obesity: Findings from 20 years of the Tehran lipid and glucose study. Int J Endocrinol Metab. 2018;16(4 Suppl). e84778. doi: 10.5812/ijem.84778. [PubMed: 30584443]. [PubMed Central: PMC6289297].

26. Azizi F, Hadaegh F, Hosseinpanah F, Mirmiran P, Amouzegar A, Abdi $\mathrm{H}$, et al. Metabolic health in the Middle East and north Africa. Lancet Diabetes Endocrinol. 2019;7(11):866-79. doi:10.1016/S2213-8587(19)301792. [PubMed: 31422063].

27. Committee on Practice B. Practice bulletin No. 137: Gestational diabetes mellitus. Obstet Gynecol. 2013;122(2 Pt 1):406-16. doi 10.1097/01.AOG.0000433006.09219.f1. [PubMed: 23969827].

28. Roeckner JT, Sanchez-Ramos L, Jijon-Knupp R, Kaunitz AM. Single abnormal value on 3-hour oral glucose tolerance test during pregnancy is associated with adverse maternal and neonatal outcomes: a systematic review and metaanalysis. Am JObstet Gynecol. 2016;215(3):28797. doi:10.1016/j.ajog.2016.04.040. [PubMed: 27133007].

29. Committee on Practice B. Practice bulletin No. 180: Gestational diabetes mellitus. Obstet Gynecol. 2017;130(1):e17-37. doi: 10.1097/AOG.0000000000002159. [PubMed: 28644336].

30. Carpenter MW, Coustan DR. Criteria for screening tests for gestational diabetes. Am J Obstet Gynecol. 1982;144(7):768-73. doi: 10.1016/0002-9378(82)90349-0. [PubMed: 7148898].

31. Boriboonhirunsarn D, Sunsaneevithayakul P. Abnormal results on a second testing and risk of gestational diabetes in women with normal baseline glucose levels. Int J Gynaecol Obstet. 2008;100(2):147-53. doi:10.1016/j.ijgo.2007.08.019. [PubMed: 18005964].

32. de Wit L, Bos DM, van Rossum AP, van Rijn BB, Boers KE. Repeated oral glucose tolerance tests in women at risk for gestational diabetes mellitus. Eur J Obstet Gynecol Reprod Biol. 2019;242:79-85. doi: 10.1016/j.ejogrb.2019.09.022. [PubMed: 31569028]

33. Horvath K, Koch K, Jeitler K, Matyas E, Bender R, Bastian H, et al. Effects of treatment in women with gestational diabetes mellitus: systematic review and meta-analysis. BMJ. 2010;340:c1395 doi: 10.1136/bmj.c1395. [PubMed: 20360215]. [PubMed Central: PMC2848718].

34. Nielsen LR, Ekbom P, Damm P, Glumer C, Frandsen MM, Jensen DM et al. HbA1c levels are significantly lower in early and late preg nancy. Diabetes Care. 2004;27(5):1200-1. doi:10.2337/diacare.27.5.1200. [PubMed: 15111545].

35. American Diabetes Association. 14. Management of Diabetes in Preg nancy: Standards of Medical Care in Diabetes-2021. Diabetes Care. 2021;44(Suppl 1):S200-s210. eng. doi: 10.2337/dc21-S014. [PubMed: 33298425].

36. Feng Y, Yang H. Metformin - a potentially effective drug for gestational diabetes mellitus: a systematic review and metaanalysis. J Matern Fetal Neonatal Med. 2017;30(15):1874-81. doi: 10.1080/14767058.2016.1228061. [PubMed: 27549367].

37. Song R, Chen L, Chen Y, Si X, Liu Y, Liu Y, et al. Comparison of glyburide and insulin in the management of gestational diabetes: A meta-analysis. PLoS One. 2017;12(8). e0182488. doi: 10.1371/journal.pone.0182488. [PubMed: 28771572]. [PubMed Central: PMC5542468]

38. American Diabetes Association. 14. Management of Diabetes in Pregnancy: Standards of Medical Care in Diabetes-2020. Diabetes Care. 2020;43(Suppl 1):183-92. doi: 10.2337/dc20-S014. [PubMed: 31862757].

39. Alves JM, Stollmeier A, Leite IG, Pilger CG, Detsch JC, Radominski $\mathrm{RB}$, et al. Postpartum reclassification of glycemic status in women with gestational diabetes mellitus and associated risk factors. Rev Bras Ginecol Obstet. 2016;38(8):381-90. doi: 10.1055/s-0036-1588008. [PubMed: 27541185].

40. Damm P, Houshmand-Oeregaard A, Kelstrup L, Lauenborg J, Mathiesen ER, Clausen TD. Gestational diabetes mellitus and long-term consequences for mother and offspring: a view from Denmark. Dia- 
betologia. 2016;59(7):1396-9. doi: 10.1007/s00125-016-3985-5. [PubMed: 27174368].

41. Tehrani FR, Hashemi S, Hasheminia M, Azizi F. Follow-up of women with gestational diabetes in the Tehran Lipid and Glucose Study (TLGS): a population-based cohort study. J Obstet Gynaecol Res. 2012;38(4):698-704. doi: 10.1111/j.1447-0756.2011.01767.x. [PubMed: 22380591].

42. Kim C. Maternal outcomes and follow-up after gestational diabetes mellitus. Diabet Med. 2014;31(3):292-301. doi: 10.1111/dme.12382. [PubMed: 24341443]. [PubMed Central: PMC3944879].

43. Buchanan TA, Xiang AH, Page KA. Gestational diabetes mellitus: risks and management during and after pregnancy. Nat Rev Endocrinol. 2012;8(11):639-49. doi: 10.1038/nrendo.2012.96. [PubMed: 22751341]. [PubMed Central: PMC4404707].

44. Excellence NIfC. Diabetes in pregnancy: management from preconception to the postnatal period. London; 2015.

45. Schafer-Graf UM, Gembruch U, Kainer F, Groten T, Hummel S, Hosli I, et al. Gestational diabetes mellitus (GDM) - diagnosis, treatment and follow-up. Guideline of the ddg and Dggg (s3 level, AWMF registry number 057/008, February 2018). Geburtshilfe Frauenheilkd. 2018;78(12):1219-31. doi: 10.1055/a-0659-2596. [PubMed: 30651660]. [PubMed Central: PMC6301211].

46. Hod M, Kapur A, Sacks DA, Hadar E, Agarwal M, Di Renzo GC, et al. The
International Federation of Gynecology and Obstetrics (FIGO) initiative on gestational diabetes mellitus: A pragmatic guide for diagnosis, management, and care. Int J Gynaecol Obstet. 2015;131 Suppl 3:S173211. doi: 10.1016/S0020-7292(15)30007-2. [PubMed: 26433807].

47. Dudley DJ. Diabetic-associated stillbirth: incidence, pathophysiology, and prevention. Clin Perinatol. 2007;34(4):611-26. vii. doi: 10.1016/j.clp.2007.09.003. [PubMed: 18063109].

48. Hackmon R, Bornstein E, Ferber A, Horani J, O'Reilly Green CP, Divon MY. Combined analysis with amniotic fluid index and estimated fetal weight for prediction of severe macrosomia at birth. Am J Obstet Gynecol.2007;196(4):333 e1-4. doi: 10.1016/j.ajog.2006.11.019. [PubMed: 17403410].

49. Zhang M, Zhou Y, Zhong J, Wang K, Ding Y, Li L. Current guidelines on the management of gestational diabetes mellitus: a content analysis and appraisal. BMC Pregnancy Childbirth. 2019;19(1):200. doi: 10.1186/s12884-019-2343-2. [PubMed: 31196116]. [PubMed Central: PMC6567433].

50. Keely E, Berger H, Feig DS, Diabetes Canada Clinical Practice Guidelines Diabetes in Pregnancy Expert C. New diabetes Canada clinical practice guidelines for diabetes and pregnancy - what's changed? J Obstet Gynaecol Can. 2018;40(11):1484-9. doi: 10.1016/j.jogc.2018.06.024. [PubMed: 30274918]. 